\title{
Demystifying Myths of Cancer
}

\section{Prakash S Bisen*}

Center for Innovative Technology, Vikrant Institute of Technology and Management, Gwalior 474005, India

Cancer is one of the major causes of mortality worldwide, accounting for 7.6 million deaths worldwide and 0.64 million deaths in India [1]. Cancer is looked upon necessarily as a disease which is prevalent in wealthy and developed countries; however it can be regarded as one of myths associated with the cancer. Of the 7.6 million worldwide deaths due to cancer in 2008 , about $70 \%$ occurred in less developed countries $[1,2]$. The deaths due to cancer are in increasing trend and is projected to kill more than 13 million people from cancer in 2030 [1]. The focus of this year's World Cancer Day was to dispel such damaging myths about cancer, with the theme - "Cancer - Did you know?" aimed to demystify common myths associated with cancer with an objective catalyze global prevention and treatment efforts [3]. Some of the myths listed in this year's campaign are:

\section{Myth 1 - Cancer is just a health issue}

Truth: Cancer is not just a health issue. It has wide-reaching social, economic, development, and human rights implications.

Myth 2 - Cancer is a disease of the wealthy, elderly and developed countries

Truth: Cancer is a global epidemic. It affects all ages and socioeconomic groups, with developing countries bearing a disproportionate burden.

\section{Myth 3 - Cancer is a death sentence}

Truth: Many cancers that were once considered a death sentence can now be cured and for many more people, their cancer can be treated effectively.

\section{Myth 4 - Cancer is my fate}

Truth: With the right strategies, a third of the most common cancers can be prevented.

The health care policies of less developed nations have been designed to cope up with communicable diseases like malaria, aids, tuberculosis etc., which claims major share of disease mortality and incidence burden in these countries. The result of such focused policies towards controlling communicable diseases have started to show fruitful results, over $50 \%$ decrease in people dying from AIDS (2005-2011) in India should be regarded as success model for disease management $[4,5]$. Such healthcare policies will definitely help in increasing life expectancy in less developed countries; however it sadly comes with a hefty price tag associated with emergence of noncommunicable diseases like cancer, which with the few exceptions shows up at more advanced age.

According to latest survey, about 0.56 million people in India died from cancer in 2010 [6]. The findings in this survey can be help us in demystifying some of the myths associated with cancer in Indian context. Cancer has equally affected lives of people living in rural or urban setup, and in contrast to existing myth of it been associated mostly with advanced age, more than $70 \%$ of fatal cancers in India occur in people aged between 30 to 69 years. A 30-year-old man in India had a $4.7 \%$ chance of dying from cancer before the age of 70 years and the respective risk for a 30 -year-old woman was $4 \cdot 4 \%$. Oral and lung cancer are two most common fatal cancers in Indian men. Most prevalent cancers in men in India (oral and lung cancers) have strong causal relation with tobacco consumption in various forms. In fact close to $22 \%$ of all cancer related deaths and around $42 \%$ of cancer mortalities in men in India are caused by tobacco. Reducing tobacco use in India by means of dedicated policies to regulate and discourage tobacco use definitely will be a significant step towards malignancies including those caused by cancer. Policy makers across world have been trying very hard to contain menace caused by tobacco, however mostly their efforts have not translated into desired results. Governments across world including Indian government found themselves precariously pulled by opposing priorities, on one had they want to set their country free from malignancies like cancer and at the same time they does not want to do something which will seriously affect their revenues earned through taxation of tobacco products and displace livelihood of huge number of people mostly underprivileged involved in tobacco industry [7]. Heavy taxation of tobacco products is touted as a effective measure, which will help in controlling tobacco use in India, however the existing taxation policy seems to be flawed as it collects little more than $70 \%$ of excise duty from cigarette and rest of it comes from more prevalent modes of tobacco use in India (i.e. beedi, chewing tobacco and others including gutka) $[7,8]$. The rise of deaths caused by tobacco is a testimony of failure of various strategies to regulate it through heavy taxation and other initiatives related with increasing awareness about tobacco's ill-effects. It is high time to realize that the revenue earned by allowing proliferation of tobacco related business can no longer support expenditure incurred by disease burden caused by it, and certainly cannot fuel nation's growth.

Cervical, stomach and breast cancers are most common type of fatal cancers among Indian women, accounting for over $41 \%$ of cancer deaths among women in India. Causal analysis of cancer deaths among women in India, projects some interesting facts like 37\% of cancer deaths are caused infection-related (cervical, stomach and liver cancers) and $18.3 \%$ of cancer deaths are caused by tobacco [6], which essentially means that around $55 \%$ of all cancer deaths in women are preventable by interventions like vaccination against human papillomavirus (HPV), helicobacter pylori, hepatitis viruses ( $\&$ \& ) and tobacco cessation. For less developed countries with limited financial resources, focus on health care policies focused on prevention and screening are obvious choice. Advances made in developed countries to treat certain cancers

*Corresponding author: Prakash S Bisen, Center for Innovative Technology Vikrant Institute of Technology and Management, Gwalior 474005, India, E-mail: psbisen@gmail.com

Received March 08, 2013; Accepted March 11, 2013; Published March 13, 2013

Citation: Bisen PS (2013) Demystifying Myths of Cancer. J Cancer Sci Ther 5 e120. doi:10.4172/1948-5956.1000e120

Copyright: @ 2013 Bisen PS. This is an open-access article distributed under the terms of the Creative Commons Attribution License, which permits unrestricted use, distribution, and reproduction in any medium, provided the original author and source are credited. 
like breast cancer, leukemia etc should be leveraged to effectively manage those cancers in India, for an instance, breast cancer mortality can be reduced significantly by encouragement on mammographic screening and administration of cost-effective drugs like tamoxifen.

Cancer has eluded researchers across the world since several decades, in their pursuit to find magic bullet which will cure cancer; however such relentless efforts have not gone completely wasted. Thanks to these efforts now we have better understanding of cancer at molecular level, and have conclusively proven heterogeneous and evolving nature of cancer cell. Heterogeneity essentially means that no two cancers are same, which has given birth to idea of personalized medicine for cancer treatment [9]. The efficacy of personalized drugs heavily depends on accuracy of biomarker to screen patient's profile. Review of health research plan document [10], gives us confidence that India's research roadmap is aligned in right direction, however its success or failure would depend on political will and commitment to provide adequate funding for such research endeavors. The war against cancer cannot be won in confines of research labs or hospitals; it requires enthusiastic participation from all corners of the society. Every one of us certainly has something to contribute in this war against cancer in various ways like spreading awareness (through campaigns, publications [11]), research, discovery, philanthropy, personal commitments (following healthy life-style, abdicating malice like tobacco and alcohol, regular screening and health checkups).

\section{References}

1. Ferlay J, Shin HR, Bray F, Forman D, Mathers C, et al. (2010) Estimates of worldwide burden of cancer in 2008: GLOBOCAN 2008. Int J Cancer 127: 2893-2917.

2. Global Health Observatory Data Repository.

3. http://www.worldcancerday.org

4. http://www.unaids.org/en/media/unaids/contentassets/documents/ epidemiology/2012/gr2012/20121120_UNAIDS_Global_Report_2012_en.pdf

5. Pandey A, Sahu D, Bakkali T, Reddy D, Venkatesh S, et al. (2012) Estimate of HIV prevalence and number of people living with HIV in India 2008-2009. BMJ Open 2.

6. Dikshit R, Gupta PC, Ramasundarahettige C, Gajalakshmi V, Aleksandrowicz L, et al. (2012) Cancer mortality in India: a nationally representative survey Lancet 379:1807-1816.

7. Rao V, Chaturvedi P (2010) Tobacco and health in India. Indian J Cancer. 47 3-8

8. http://finmin.nic.in/press_room/2012/1440.pdf

9. Potti A, Schilsky RL, Nevins JR (2010) Refocusing the war on cancer: the critical role of personalized treatment. Sci Trans Med 2: $28 \mathrm{~cm} 13$.

10. XII Plan Document (2012) Department of Health Research, Ministry of Health and Family Welfare - Government of India.

11. Bisen PS, Khan Z, Bundela S (2013) Biology of Oral Cancer - Key Apoptotic Regulators. pp 268. Boca Ratan, Taylor and Francis, CRC Press. 